\title{
REFLEXÕES SOBRE OS VINTE ANOS DE EXPERIÊNCIA DO GRUPO DE TEATRO TÁ NA RUA
}

\begin{abstract}
Amir HADDAD 1
- RESUMO: O artigo trata dos conceitos de um teatro público e de um teatro privado, a partir do surgimento da burguesia capitalista. O capitalismo estabeleceu um conflito entre as manifestações públicas (festas dramáticas) e o teatro de recinto fechado. As fontes brasileiras para um teatro público são vistas pela restauração e recuperação das nossas origens mediterrâneas em oposição ao pensamento protestante da América do Norte e Europa.
\end{abstract}

- PALAVRAS-CHAVE: Teatro público; teatro privado; burguesia capitalista.

Existe um teatro imanente na cidade. Há uma possibilidade teatral imanente no cidadão e nos ritos de convivência, não prevista na vida da cidade e, conseqüentemente, não considerada, embora continuamente se manifeste - numa festa, numa barraca de cachorro-quente, num camelô que vende alguma coisa, em tudo. Parto do princípio de que o que provoca isso é a divisão que se estabeleceu, ao longo dos últimos trezentos anos, entre teatro e cidade, entre cidadão e artista. A cidade mudou, o teatro não.

Venho trabalhando a idéia de que a cidade é por si teatral, é dramática e que o teatro está impregnado dessas possibilidades de expressão. Idéia que me leva a eliminar o mais possível a diferença entre cidadão e artista e a criar um espaço onde é a cidadania que se manifesta artistica-

1 Diretor do grupo de teatro Tá na Rua. Rio de Janeiro - 22290-040 - RJ. 
mente; não se trata de separar uma parte da cidade para celebrar o teatro ou pegar um pedaço da cidade e colocar dentro de um edifício para que ela esteja ali simbolizada, mas sim pensar toda a cidade como uma possibilidade teatral - ela é o espaço de representação, suas ruas e edifícios são a cenografia e os atores, os cidadãos.

O produto mais avançado que venho desenvolvendo no Brasil, junto ao grupo Tá na Rua, é a realização de grandes espetáculos-festas, atualmente concebidos como imensos cortejos, a que denominamos liturgia carnavalizada.

Durante anos, nossas pesquisas se desenvolveram em cima de um teatro clássico, Morrer pela pátria (1936), de Carlos Cavaco: três atos, com unidade de tempo, espaço e ação. Era um folhetim fascista.

A tentativa de elaborar um espetáculo sobre esse texto de pensamento fascista, autoritário, em que ficasse claro que nós não éramos fascistas, levou-nos a mergulhar em verdadeiro estudo arqueológico sobre a formação social brasileira, buscando o profundo entendimento dos valores ali defendidos - Deus, Pátria e Família -, fortemente arraigados na formação de nosso povo, além de permitir um contato com nossas contradições e realizar um longo e profundo trabalho de remoção das identificações.

Se, por um lado, o processo então realizado nos proporcionou descobertas importantes em relação ao jogo do ator, levando-nos a uma atuação desenvolvida, que apresentava uma realidade, em vez de representá-la e que permitia que nos reconhecêssemos muito próximos das investigações de Brecht e de sua teoria do distanciamento, por outro, a demolição da linguagem-estrutura do teatro convencional foi revelando outras possibilidades, dando passagem a uma linguagem cada vez mais livre, mais aberta e que identificávamos como mais popular.

A confirmação de nossas descobertas, porém, só se deu realmente no momento em que fomos para a rua; foi só então que começamos a entender, na prática, que estávamos conquistando outra linguagem. Foi só então que o trabalho realmente começou a se modificar, que as indagações a respeito do palco italiano, da dramaturgia, sobre as maneiras de trabalhar o ator, tudo isso que ficava mais ou menos vago ou teórico, começou a ter concretude.

Quando, em 1980, saímos para a rua, não tínhamos nenhuma intenção messiânica ou evangélica, não fomos salvar ninguém, fomos nos salvar, tampouco pretendíamos levar cultura para o povo. Fomos para a rua dar continuidade às nossas investigações sobre o espaço - e tivemos muitas informações sobre as coisas de espaço. Mas a revelação maior foi trabalhar com o público que desconhecíamos, sobre o qual não sabíamos 
nada. Foi o contato com uma platéia heterogênea - o povo, na sua concepção mais imediata - que nos obrigou a nos desarmarmos, a rever nossas atitudes, nossos conceitos, nosso modelo de ator, nossa comunicação com o espectador. E, a partir daí, a repensar a dramaturgia, a repensar todo teatro e a chegarmos ao que poderíamos definir como uma linguagem popular, como em Shakespeare, em Molière, os gregos.

A saída para a rua nos levou às origens do teatro, do que pensávamos e sentíamos ter existido antes da captação da linguagem teatral pela burguesia, no início dos tempos modernos - período em que se instalou a hegemonia da Razão, rompendo (mais nitidamente, ao menos) o equilíbrio corpo/mente e em que a fala passou a ter mais força. Caminhamos, assim, em direção ao resgate de uma história do teatro que não é contada nos manuais: a do teatro popular; em direção do popular que existe em cada um de nós.

Porque nenhum de nós era popular! Alguns de nós vivíamos nos endereços mais sofisticados da cidade do Rio de Janeiro, freqüentávamos faculdades... Éramos de classe média, brancos, universitários! Todo o processo que deslanchamos, porém, tinha muito a ver com um sentimento nosso de rebelião contra o estabelecido - sentimento que se fortalecia diante da realidade política que então vivenciávamos, em um país submetido a um governo ditatorial.

Peter Burke, historiador, em seus estudos sobre cultura popular, ao investigar o aparecimento da dicotomia cultura erudita/cultura popular que surgiu justamente nessa fase em que se estruturou a sociedade burguesa - faz uma análise muito interessante sobre a obra de Bakhtin e considera que este, quase explicitamente, desenvolve o pensamento de que popular é tudo aquilo que se rebela contra o estabelecido. Análise que auxilia o processo então vivido pelo grupo.

Durante anos estivemos na luta contra o estabelecido, insatisfeitos, sem uma proposta para substituir. Durante anos ficamos mudos: não falávamos língua alguma. Quando desmontamos o estabelecido dentro de nós começaram a aparecer outras possibilidades: surgiu um teatro que reconhecíamos como popular. Como no Carnaval, quando o rei momo está reinando e tudo que é estabelecido é abandonado e reina a desordem. Ao sairmos para a rua, encontramos o outro lado; viramos o teatro de cabeça para baixo, como um saltimbanco - o símbolo de nosso grupo, Tá na Rua.

Quando começamos ir para a rua, praticamente não havia teatro de rua no Brasil. Nosso referencial eram os camelôs e os artistas de rua; eram aqueles camelôs que vendiam mágicas, vendiam remédios para 
calo e mil outras bugigangas. Nós os observávamos enquanto faziam teatro para vender suas mercadorias: como seguravam a roda, como "esquentavam" o espaço de atuação, como brincavam com o público - um público que eles, em momento nenhum, ignoravam, pois sabiam que ele só permaneceria para assistir a suas demonstrações se soubessem conquistá-lo.

Conhecimentos práticos que levamos anos para aprender - para saber ocupar o espaço da roda, para saber abri-la e mantê-la aberta. Depois tivemos que aprender também quais eram as diferenças entre nós e aqueles camelôs. Por que eles precisavam de uma roda de uma determinada maneira? Por que nós precisávamos de outra?

Paralelamente, outras fontes eram utilizadas na formação de nossa linguagem; o contato com os ritos religiosos afro-brasileiros, como a gira de umbanda e o candomblé, possibilitava o estabelecimento de relações muito íntimas entre os processos neles desenvolvidos e as formas de representação que buscávamos alcançar em nosso trabalho.

Pouco a pouco, pudemos ousar mais, alargar nosso espaço de representação. A participação no desfile na escola de samba Beija-Flor (Carnaval de 1989) nos deu a oportunidade de testar em alta escala todo conhecimento adquirido em nossas pequenas rodas. Passamos a realizar grandes espetáculos, grandes festas, ocupando grandes espaços.

Mas o próprio movimento de transformação do trabalho nos fez ver que havia raízes mais ancestrais que nos levavam a recusar aquele teatro que se caracterizava como linguagem de representação da elite cultural; raízes que estavam ligadas às origens religiosas do teatro. Religio/religare - restabelecer as relações entre os homens e seus deuses, entre os homens e seus pares, entre os homens e as cidades onde eles viviam. Essas eram nossas necessidades mais profundas: retomar contato com o sentido de comunhão que é o próprio teatro. Sentindo que se exige uma participação muito mais ativa e até mesmo direta de seu público e o torna pleno do sentido de festa.

Utilizando textos narrativos - cordéis, autos sacramentais -, passamos a perseguir uma idéia: a da cidade em festa e o teatro acontecendo como parte desse contexto. $\mathrm{O}$ teatro deixando de ser um produto cultural isolado num espaço, para se transformar em usufruto da cidade toda. Experiências que se concretizaram, abriram espaço para aprofundamentos ainda mais amplos sobre as questões que envolvem nosso trabalho.

A nossa recusa em relação ao teatro burguês - hoje nós sabemos identificar melhor - não se limitava a diferenças políticas e/ou ideológicas. Ela se relacionava também à mudança que ocorrera intrinsecamente 
no teatro, a partir do momento em que este sofrera um deslocamento em seu eixo "religioso" e passara a ser informado por uma ética e uma estética protestantes. Em nossos sentimentos, havia um enfado em relação ao teatro "protestante", desenvolvido pela burguesia capitalista; em relação a esse teatro pragmático, pai do realismo, que tem dificuldade com os grandes espaços, em falar com a cidade inteira. Porque esse teatro exclui parte da cidade! A burguesia criou uma sala, a que chamou de teatro público, mas que, em verdade, é uma sala feita para ela!

No momento em que abri minha cabeça a esse respeito, mudaram as fontes de informação sobre o teatro que atuam dentro de mim, que alimentam o meu trabalho. Se nós queremos nos livrar do teatro da burguesia, temos que beber em outras fontes ou não teremos recursos para criar nossos espetáculos. Vivemos num mundo protestante, mas nossa cultura, no Brasil, é de origem católica, medieval e também islâmica.

Comecei a recuperar fontes vivas dentro de mim. E aí, o que aflorou foram procissões religiosas que vi na minha infância e das quais participava toda a cidade. Principalmente uma, a mais dramática de todas, que era emocionante e da qual adorava participar - a procissão do encontro. Uma parte dela saía de uma das igrejas da cidade, ao mesmo tempo que uma outra parte saía de outra igreja; e ambas se encontravam em determinado ponto. Uma trazia Jesus Cristo carregando a cruz e a outra, Maria; quando se cruzavam na rua, ela via o filho sendo castigado. Eram aquelas duas estátuas balançando no alto, apoiadas nos ombros das pessoas. Mas era de impacto fenomenal!

A partir daí, fontes religiosas que informavam meu trabalho foram ficando mais claras e um novo momento foi se construindo. Tive de começar a pensar o meu teatro com essa possibilidade: o mundo inteiro está no espetáculo, não só um pedaço do mundo. E aí, o que faço tem a ver com o teatro de Shakespeare, com o teatro espanhol, com as procissões de Sevilha... Tem a ver com tudo.

Ao rompermos com os procedimentos éticos da burguesia capitalista protestante, partimos para uma outra realização, para a construção de um outro mundo, dentro do qual a vida comunitária e a cidade estão incluídas. Passamos a agir na contra-mão do pensamento neoliberal burguês.

Os nossos espetáculos-festas nos revelaram o quanto o aspecto ritual está presente nas grandes manifestações, quando a cidade toda fica envolvida por um mesmo movimento e se permite a, como num grande Carnaval, virar o mundo de cabeça para baixo. As festas apontam para questões utópicas, aflorando a possibilidade de interação entre as pes- 
soas, entre o povo e seus governantes, e, momentaneamente, a cidade é feliz.

Todo meu trabalho tem se desenvolvido para dar ao cidadão a possibilidade de se expressar além dos recursos cotidianos que ele tem. A sociedade capitalista privatiza e especializa - porque esse é um sentido prático, que interessa ao dinheiro, ao lado material... Nós desmontamos esse esquema. Eliminamos essa idéia pragmática de que uns fazem uma coisa, outros fazem outra. Tudo é público e nada é especializado. O cidadão e o artista são as mesmas pessoas e as representações teatrais se transformam em acontecimentos públicos.

Nossos procedimentos, desde o início de nossas investigações, permitiram o desenvolvimento de um jogo de ator mais desarmado e que não considerava nem permitia que as pessoas o considerassem como especial. Um jogo que faz a platéia ficar à vontade e se sentindo autorizada a interferir, porque quer fazer aquele jogo também. E o desenvolvimento disso - da noção de que todos sabem/ter capacidade para fazer; dessa qualidade que está latente em todos - reforça a cidadania.

Então a nossa atuação é uma rebeldia, é um abandonar o regime vigente e buscar outras possibilidades fora dos padrões tradicionais, da sociedade burguesa que é privatizadora e especializadora. Resulta do pensamento que norteia nosso trabalho e que afasta a idéia de que só poucos são artistas e os outros são espectadores; de uma divisão do mundo entre passivos e ativos. Todos são sujeitos ativos, todos têm participação e interferem na história.

Tiramos a idéia de privatização, transformamos nossas representações numa festa pública e tiramos também a idéia de que só pessoas altamente especializadas podem fazer aquele trabalho. Nossa idéia é que todas as pessoas, toda a cidade pode participar; não é nenhuma especialidade o que queremos exibir. Nossos cortejos trazem não os artistas oficiais da cidade, mas pessoas comuns que se expressam artisticamente. Não há nenhuma exigência de experiência teatral. São cidadãos, pessoas do povo que estão ali, fazendo isso - expondo suas possibilidades de expressão.

Nós só conhecemos o lado do cidadão que dá duro, bate pedra, trabalha, não tem alegria, não tem prazer, anda de cabeça baixa. De vez em quando toma um pileque, mas não entra em contato com nada. A festa proporciona a existência de um espaço em que ele se vê livre de seus papéis cotidianos, em contato com sua possibilidade de manifestação, que é maior que a máscara cotidiana que ele usa e que não leva em consideração o seu lado criativo. Esse é o momento em que ele pratica o exer- 
cício dessa ludicidade e assume um único papel - o de ser humano livre, criativo, fértil, transformador.

Da mesma forma a cidade, quando colocamos todos os cidadãos na rua, começa a entrar em contato com o outro lado dela, diferente do cotidiano - o lado que faz quadrilha, que faz dança, que faz capoeira, teatro, banda, fanfarra. E ela se percebe como coletivo. Na medida em que ela é tocada por esse aspecto cultural comum, que seus habitantes começam a se sentir parte dela, plenamente, temos ali um povo se manifestando. E quando entra o povo, entra o artístico, o carnavalizado, a cultura, a produção do ser humano que é dali.

Hoje, a nossa festa, o nosso espetáculo, tem essa sustentação ideológica. Temos clareza sobre quais as tendências com que estamos trabalhando, sobre quais fluxos de conhecimento do ser humano estão nos orientando.

O produto mais avançado de nosso trabalho - os nossos cortejos não é um produto de mercado, uma beleza a ser vendida. É um produto que procura contribuir para o crescimento das pessoas; é para consumo da sociedade como um todo e os temos realizado por meio de órgão públicos.

Nós os reconhecemos como liturgias carnavalizadas - festas que harmoniosamente misturam o sagrado e o profano. Por meio deles, procuramos restaurar alguns mitos, algumas celebrações da sociedade, recuperando essa comunhão que vem se perdendo, cada vez mais. Voltamos na história, para podermos ir adiante.

É por esse caminho que estamos aprendendo a fazer um espetáculo híbrido: com movência e, ao mesmo tempo, com paradas onde algumas cenas são apresentadas. Com ele, estamos aprendendo a desenvolver uma nova dramaturgia, diferente da tradicional e que se aproxima das narrações dramáticas presentes em vários momentos da história do teatro, desde os povos antigos, como a procissão de Osíris, no Egito, em que representavam a vida do deus; como o Taziyé - O martírio de Hassan e Hussein, na Pérsia, onde os maometanos contam teatralmente, numa praça, a história da sangrenta guerra que se instalou entre os herdeiros de Maomé, após sua morte. Ou ainda, como alguns grupos africanos contemporâneos ligados à tradição, com suas danças teatralizadas.

Atualmente, estamos descobrindo um caminho - o do criar a narrativa dramática por meio da escrita do próprio espetáculo, afastada de qualquer literatura. Nós não partimos para o diálogo. Começamos a experimentar nos espaços mais amplos essa possibilidade de escrever um espetáculo "sem diálogo". É um espetáculo escrito no espaço e com o 
corpo, tanto dos atores quanto das pessoas que passam, com a apresentação de carros alegóricos. Mais do que na fala, na palavra, os sinais se encontram nas atitudes do ator, na atmosfera do espetáculo, nos desenhos, nas cores nos objetos.

Temos trabalhado sobre grandes festividades religiosas, como o Natal, e profanas, como o Carnaval. Nos autos de Natal que fazemos, a história já está arraigada na mente, no coração do povo. Basta jogar um sinal forte, que eles reconhecem rapidamente. Tem, dentro do povo, a força dos mitos gregos.

Os primeiros autos foram realizados em espaços abertos, mas sempre ocupando um único espaço, geralmente uma praça que procurávamos transformar em um grande mercado, como as feiras medievais.

Nossas experiências atuais, nesse sentido, ao longo dos últimos anos, têm nos feito levar adiante o aprendizado que tivemos trabalhando com os grandes desfiles das escolas de samba do Rio de Janeiro e com outros tipos de cortejos dramáticos que se multiplicam pelo país, guardando sua origem medieval de autos populares, como o Maracatu, Bumba-meu-boi, Folias-de-reis etc. Junto a esse lado profano, colocamos nossas tradições seculares religiosas de origem católica e transformamos nossos espetáculos em verdadeiras liturgias carnavalizadas, com cortejos que se movimentam por toda a cidade levando em seu bojo de três mil a cinco mil participantes e que poderão se locomover sem interrupções até o local onde se darão encenações públicas de natureza épico-cultural, ou então tendo paradas intermediárias, onde essas apresentações serão feitas, como estações de algumas manifestações religiosas nômades da Igreja católica.

Cremos assim estar juntando o sagrado ao profano e procurando dessa maneira tocar o coração do cidadão e despertar nele o sentido de religação das festas e celebrações, desenvolvendo ao teatro sua função pública social original "quente" e garantindo para ele um lugar num futuro imprevisível de realidade virtuais "frias". Dessa maneira, enxergamos o teatro como a possível arte do futuro, a única talvez que estará se mantendo dentro do propósito de fornecer ao ser humano espaço para o seu sentimento gregário e comunitário, contribuindo assim para a construção de uma nova cidade e uma nova sociedade em que as diferenças sociais e culturais poderão ser administradas e o sonho utópico da construção da "Cidade Feliz" possa ser retomado. 
HADDAD, A. Reflections about twenty years experience of the theater groups "Tá na Rua". Trans/Form/Ação (São Paulo), v.24, p.153-161, 2001.

- ABSTRACT: The paper deals with the concepts of a public theater and a private theater from the begining of the capitalist bourgeoisie. Capitalism established a conflict between public events (dramatic feasts) and the indoor theater. The Brazilian sources of a public theater are seen through the restoration and recuperation of our Mediterranean origins in opposition to the protestant thought of North America and Europe.

- KEYWORDS: Public theater; private theater; capitalist bourgeoisie. 